\title{
Erratum to: A Generalization of the von Mises Criterion for a Single Crystal with a Hexagonal Crystal Lattice
}

\author{
A. M. Vlasova ${ }^{a, b, *}$ and A. G. Kesarev ${ }^{a}$ \\ ${ }^{a}$ M. N. Mikheev Institute of Metal Physics of Ural Branch of RAS, Ekaterinburg, 620108 Russia \\ ${ }^{b}$ Ural Federal University, Ekaterinburg, 620002 Russia \\ *e-mail: alisa@imp.uran.ru \\ Received November 6, 2020
}

DOI: $10.3103 / \mathrm{S} 0025654420660012$

The name of the second authors should read A. M. Vlasova and A. G. Kesarev.

The original article can be found online at https://doi.org/10.3103/S0025654419080107 